\title{
13
}

\section{Developing Strategies to Harness the Power of Parallel Entrepreneurship in Africa}

\section{Eskor John}

\section{Introduction}

Entrepreneurship is an omnipresent phenomenon in Africa. Everyone wants to use his or her zeal and creativity to develop monetized strategies for engaging with the continent's opportunities and challenges. The success of entrepreneurs such as Kenya's Chris Kirubi (Nkem-Eneanya 2015) in harnessing economic potential on the continent have been celebrated both domestically and internationally. Less is written about, however, is the entrepreneurial culture from which these successes have sprung. One hears anecdotally instead of the teacher who, outside of the classroom, runs a tourism business, electronics distribution center, and hair salon or of the musician who sets up a language center, art studio, and bakery. What may seem like the sporadic pursuit of a random assortment of business ventures to many in the West is, in fact, evidence of the fruitful and distinctively African business phenomenon of parallel entrepreneurship.

E. John $(\bowtie)$

Marigold Asset Management, London, United Kingdom

(C) The Author(s) 2017

403

B. Ndemo, T. Weiss (eds.), Digital Kenya,

DOI 10.1057/978-1-137-57878-5_13 
Early entrepreneurship studies often regarded entrepreneurs as a homogeneous group. More recently, scholars have recognized that entrepreneurs have different ownership propensities. Parallel entrepreneurship, a sub-type of the habitual entrepreneurship, is entrepreneurship in which the actors are involved in a number of businesses simultaneously (Fierro and Noble 2013). Known also as concurrent entrepreneurship, it is found around the world and is particularly evident at the international level, in the form of conglomerates. Parallel entrepreneurship in Africa is unusual in the way it permeates the business culture of the continent. The propensity to own and operate a number of businesses simultaneously does not appear to be influenced by gender, age, or wealth.

The motivation behind this chapter is to identify some of the most salient factors related to parallel entrepreneurship - factors that, if better understood and supported, have the potential to make a significant contribution to the economic transformation of the region. By their very nature, entrepreneurs owning multiple ventures are more experienced than their peers operating single businesses, and studying them can enhance understanding of entrepreneurship more generally. This chapter explores the contextual factors contributing to the growth of entrepreneurship in Africa and the prevalence and implications of parallel entrepreneurship in particular. The chapter also recommends ways of supporting and developing parallel entrepreneurship in the future.

\section{Parallel Entrepreneurship in Africa}

Africa's contemporary culture of entrepreneurship has flourished as a consequence of two broad factors - the improvement of economic conditions and the change in social attitudes.

Thanks to improved political stability and economic reform in many countries, Africa's growth rate in the twenty-first century so far has been unprecedented. Average annual growth on the continent increased from $1.81 \%$ in $1980-1989$ to $5.28 \%$ in $2000-2010$ and has remained $2 \%$ above that of the world economy in the 2008-2012 postfinancial crisis period. Many African countries have posted strong average growth rates of around $6 \%$; some have even reached double digits (UNCTAD 2014). 
Among the beneficiaries of Africa's economic renaissance are entrepreneurs who have been presented with a plethora of revenue-generating opportunities. Whether it is tapping into the buoyant weddings market, setting up affordable boutique hotels, or providing micro-credit programs, countless business activities are being explored. Such an abundance of opportunities has led to a burst of new entrepreneurial activity on the continent. A recent Global Enterprise Monitoring (GEM) report evaluating the health of entrepreneurship globally found that the SubSaharan Africa region has the highest number of people involved in earlystage entrepreneurial activity in the world. In particular, Nigeria and Zambia had the highest representation of entrepreneurs, with approximately $40 \%$ of those between the ages of 18 and 64 owning a company less than 3.5 years old (GEM 2015).

As to the change in social attitudes, throughout the twentieth and early twenty-first century, formal employment was the overwhelming preference for African citizens. In recent times, however, entrepreneurship and, in particular, opportunity-driven entrepreneurship (versus necessitydriven entrepreneurship) have become increasingly popular career choices. According to a report on entrepreneurship in Africa by Omidyar Network and Monitor Group (ONMG), $49 \%$ of Nigerians, $76 \%$ of Kenyans, and $78 \%$ of Ethiopians believe becoming an opportunitydriven entrepreneur is a desirable choice (ONMG 2013). This finding highlights the fact that, because of the level of economic potential in Africa, people are increasingly seeing entrepreneurship as a way to capitalize on opportunities, and their efforts are being positively received by their communities.

As entrepreneurship has flourished, so has parallel entrepreneurship. A number of entrepreneurs are taking advantage of improved economic conditions by exploiting different opportunities simultaneously, leading to the emergence of parallel entrepreneurship in new areas. A 2012 study by the IMANI Center for Policy and Education focusing on Ghanaian, Nigerian, and Kenyan entrepreneurs found that the surveyed entrepreneurs owned an average of six businesses each (The Economist 2012). This finding requires one to look beyond the factors that have contributed to the rise in entrepreneurship in general in the region-the improved economic conditions and shifting social attitudes - to identify the more 
specific factors and challenges that are influencing African entrepreneurs' decisions to operate a number of businesses simultaneously.

\section{Unpredictable Business Environment}

The African business environment is vulnerable to a number of destabilizing factors that can interfere with strategic plans and operations. In particular, political violence is once again a pressing matter in the region, with the number of deaths from political violence rising sharply since 2010 to approximately 40,000 over the period (Bugnacki 2015). The recent phase of violence is highly concentrated in a small number of high-profile conflicts - the Boko Haram insurgency in Central and West Africa, the Second Libyan Civil War in the northern Sahara, and the al Shabaab insurgency in the Horn of Africa, to the east. These conflicts serve to increase the perception of risk in the region among entrepreneurs, and as a result, parallel entrepreneurship serves as a way to diversify from a single company's revenue.

Furthermore, whereas the stop-go policies that typified Africa's postcolonial period have abated, corruption is still a pressing issue that scars Africa's entrepreneurial landscape. According to Transparency International, five of the top 10 and nine of the top 20 most corrupt nations in the world are in Africa (Transparency International 2014). Because an entrepreneur has no way of predicting when or how a corrupt practice or action will undermine his or her business, it is unsurprising entrepreneurs seek to diversify their income away from a single revenue source.

\section{Lack of Quality Middle Managers}

Africa's meteoric growth in the last decade has not generated the number of large businesses that might have been expected. One of the biggest challenges to building scalable businesses is the absence of skilled middlelevel managers. Adcorp, a South African labor market specialist, reported in 2013 that the middle-management issues in South Africa, which are also relevant across Africa as a whole (Rigoglioso 2011), can be attributed 
to three causes - the emigration of high-skilled workers, the immigration restrictions placed on high-skilled foreigners, and a dysfunctional education system. Adcorp also reported that, at the time its study was conducted, 244,400 management positions were unfilled in the South African private sector (Adcorp 2014). One impact this skills shortage has on entrepreneurs is potentially to limit their ability to truly scale a business. In order to adapt to this factor, many entrepreneurs may instead choose to grow and maintain their businesses at medium-size levels (Bindra 2012).

\section{Unemployment}

A lack of jobs and poor job security are two of the biggest contradictions in Africa's growth story (Mead 2012). The continent is known for being home to more than half of the world's 20 fastest-growing economies in the last 5 years (Hauge 2014). However, a number of these countries have relied on capital-intensive and mineral-extractive initiatives to turbo-charge their growth, and job creation has not grown at a similar rate (Taylor 2015). In addition, the scarcity of jobs is most pronounced in the youth population (ages 15-25 years). The young represent more than $60 \%$ of the continent's total population and account for $45 \%$ of the total labor force (African Economic Outlook 2008). However, Africa has been unable to realize the benefits of having such a sizeable working population, because of the gulf between the skills this population possesses and the skills employers require. As a result, the World Bank estimated, youth account for some $60 \%$ of all unemployed Africans (Filmer and Fox 2014).

The interconnections between unemployment and parallel entrepreneurship are represented by the concept of necessity entrepreneurshipwhich refers to entering into entrepreneurship primarily as a means of survival versus exploiting a business opportunity. In particular, when full-time employment is not a viable option, identifying and pursuing a business opportunity become the best alternative. Survival instincts and entrepreneurial zeal have resulted in Africans using entrepreneurship as a partial remedy to youth unemployment. These entrepreneurs are working aggressively to generate lifesaving income versus exploring a profitable market opportunity. 


\section{Implications for Entrepreneurial Action}

The prevalence of parallel entrepreneurship in Africa has significant implications for the shape and behavior of businesses on the continent. Successful parallel entrepreneurs are inarguably experienced business founders. As such, they are expected to have acquired the knowledge and skills necessary to develop strategies to overcome common problems in new venture and thereby be more successful business starters. Below are some of the issues of particular concern to parallel entrepreneurs that require more attention in policy, research, and practice.

\section{Legal Structures}

Entrepreneurs need to have a good understanding of the legal structure available to them when establishing a business portfolio. In general, entrepreneurs can opt for one of two choices-they can create a corporation or limited liability company (LLC) for each venture, or they can form a holding company that owns the individual corporations and LLCs constituting the entrepreneur's multiple ventures. Evaluating the pros and cons of both options is beyond the scope of this chapter. But it should be noted that African entrepreneurs need to be aware of the way these structures can affect the operation of their portfolios, especially with regard to their implications for taxes and profit distribution. Given the fact some foreign investors see the complex ownership structures of some African businesses to be a deterrent to investment (The Economist 2013), it would appear that selecting the appropriate legal structure might not only facilitate the operating of a portfolio of businesses but also entice investors looking to provide growth capital.

\section{Hedging}

The issue of hedging is of particular relevance to a parallel entrepreneur. Instead of owning a collection of related businesses, parallel entrepreneurs looking to circumvent company-specific risks in Africa's business environment often choose to own a portfolio of unrelated businesses-a 
strategy related to the old adage "Don't put all your eggs in one basket." This notion resonates strongly with African entrepreneurs, who know they must always have an alternative, or a plan B. Regulatory uncertainty and other forms of instability mean that one's revenue forecasts can be exposed to significant variability. Consequently, owning an additional one, two, or three businesses becomes particularly appealing, because these other businesses may be able to help balance out the health of one's overall portfolio. This strategy is most effective when the businesses in question are in unrelated fields, as is the case with, for example, the Muguku family in Kenya (with businesses in real estate, education, and poultry farming), where a decline in a particular industry's profitability probably will not affect the other businesses in one's portfolio.

\section{Synergies}

Managers of parallel businesses need to seriously think about how resources across their businesses are shared. Whether operating a large- or small-scale collection of companies, a parallel entrepreneur can transfer resources directly between operations in order to insulate a business from a sudden shock. This is particularly useful in the African business environment, where unforeseen catastrophes are common, and bank lending rates tend to be punitively high.

At the same time, however, cross-subsidization can result in an inefficient allocation of resources across a business portfolio when, for example, failing businesses continue to receive support from stronger-performing entities in the portfolio. This phenomenon has been well covered in the Western context through research on the behavior of conglomerates (Almeida and Wolfenzon 2006) and has been cited as one of the major drawbacks of these types of business endeavors. And although its intentions as a business strategy are understandable, the effect of suboptimal cross-subsidization can be to prolong the life of a subpar entity-as scarce resources are repeatedly diverted from a promising entity to a laggard, thereby ensuring that the promising entity is unable to use the resources to strengthen its own position. Furthermore, the prolonging of a failing business also has the potential to be a counter-productive measure if 
management is disincentivized from making meaningful changes thanks to the guarantee of funds irrespective of performance.

\section{Recommendations}

Parallel entrepreneurship is an omnipresent aspect of Africa's business landscape that has been shown to be a key driver of wealth creation (Rosa 1998; Westhead and Wright 1998). It has also been shown to be an important component of Africa's economic development (Balunywa 2009). Given the importance, then, of parallel entrepreneurship in the African economic landscape, following set of recommendations aim to provide suggestions to key stakeholders in the community for making parallel entrepreneurship more effective.

\section{Entrepreneurs}

Entrepreneurs must consider what kind of organizational structure is most appropriate for their portfolio. The traditional hierarchical model of organization is derived from European military practice (Short 2008), in which a clear chain of command and authority travels vertically downward from a chief executive officer (CEO) to department managers and thence to individual workers. In this model, all employees have a clear understanding of their roles and responsibilities, and the organization is able to operate in a predictable and unified way. This kind of structure is useful for some of the strategic considerations a parallel entrepreneur must face.

However, when dealing with a collection of diverse operations, as is the case in parallel entrepreneurship, flexibility is required because of the complexity of running the multiple ventures and the need for a wider range of expertise. In such a situation, an individual is unlikely to have sufficient knowledge to make key decisions about all ventures in his or her portfolio or to be aware of all the consequences a decision about one venture might have for the other ventures. Consequently, a hierarchical structure may be unsuitable for the kind of mixed decisionmaking 
required by the portfolio in various situations. A parallel entrepreneur may therefore want to develop a "flat" structure for his or her organization-a structure that to some extent shares decisionmaking power and influence across the workforce. The structure is intended to remove layers of bureaucracy in a business, allowing individuals to come together in informal and autonomous clusters and allowing key decisions to be made at local levels in faster and better-informed ways - and it may be appropriate for the kinds of strategic decisions that require creativity and innovation, such as those pertaining to incubation and recognizing synergies as well as those that require rapid responses to local market signals, such as hedging and sharing resources across a portfolio.

In addition to determining the appropriate organizational hierarchy for one's business, the parallel entrepreneur also needs to identify optimal ways of managing a number of businesses simultaneously. One model that is growing in prominence in the tech world-because of the success of companies like Idealab and Betaworks, in America-and that is worth consideration in the current context is the start-up studio model, which involves setting up a company that builds several companies in parallel via reusable infrastructure and resources.

Proponents of the model have cited focus and collaboration as key benefits (Nesta 2014), with entrepreneurs bringing together a team that focuses intensely in the product development stage while collaborating and using existing knowledge obtained from developing other products. In the African context, the studio model could be used as a way to hone in on pressing problems faced by the community. This approach has been adopted by Foresight Ventures, a Kenyan-based start-up studio aiming to create and commercialize products that solve pressing problems in the region.

Although the start-up studio model is an exciting prospect, there are certain challenges that an aspiring parallel entrepreneur should consider before going down this path. First, the approach is capital intensive, because funding is required to build the necessary infrastructure and recruit a talented cross-functional team. Second, if the entrepreneur is unable to use internal resources to meet the required capital target, then pitching the business to an investor might be a challenge, because the entrepreneur would need to convince the investor not only 
of the viability of the product(s) in question, but also of the merits of funding a special team in a co-working space. (The latter requirement is a particular challenge, because very little data exist on the track record of the studio model.)

\section{Investors}

A consideration that investors should give to parallel entrepreneurship in Africa is how the prevalence of simultaneously owning a number of businesses affects the traditional concept of holding an equity ownership stake in a company. Given the myriad of interconnected entities owned by entrepreneurs on the continent today, investors should consider more unorthodox approaches to investing. For example, rather than take an equity stake in a company per se, investors may wish to identify a continuously successful parallel entrepreneur and take an equity stake in his or her future earnings. This model, known as a human capital contract, has long been advocated by a number of leading economists, including Milton Friedman (Friedman and Kuznets 1945) and has the potential to provide much-needed capital to capable parallel entrepreneurs.

However, until now, past attempts to explore human capital contracts in the West have proven unsuccessful. In the 1970s, Yale University attempted to replace traditional student loans with human capital contracts under its Tuition Postponement Option but ended up cancelling the program. Other attempts to use human capital contracts in the education sector have also proven to be a failure, primarily because of the issue of adverse selection (NYT 1999), meaning that students who opt into human capital programs can tend to be the students who expect to pursue low-income careers and consequently are less likely to repay their full share of the loans. Another issue that has affected the performance of human capital contracts is moral hazard, meaning that the borrowers can tend to be discouraged from maximizing their income and are instead encouraged to focus on non-wage-based forms of compensation, such as better benefits (Simkovic 2011).

Although the issues of adverse selection and moral hazard could still arise if the human capital contract approach were applied to parallel 
entrepreneurs, a key difference between the students and the parallel entrepreneurs is that it would be the entrepreneurs with a proven record of successfully running businesses who were the ones selected for funding. These entrepreneurs, who have demonstrated a willingness and ability to succeed, would be unlikely to deliberately underperform after receiving funding. However, a challenge investors would face would be to enforce the contract, because of the underdeveloped nature of the regulatory framework around human capital contracts.

\section{Government}

Government policy needs to tackle some of the obstacles that currently restrict the potential of parallel entrepreneurships, including lack of access to financial capital and human capital (in the form of quality management).

A large number of Africa's parallel entrepreneurs are micro- or smallscale operators at the early stages of business development who struggle to obtain capital in the form of affordable loans. Currently, in several African nations, including South Africa, Nigeria, and Tanzania, governments have tried to increase the volume of credit channeled to smalland medium-size enterprises via credit lines and partial credit guarantees (PCGs) (Berg and Fuchs 2013). However, the success of these schemes has been limited because of the terms and conditions applied as part of PCGs. Issues including coverage ratios, fees, payment rules, and collateral requirements have limited the potential of government efforts. In Tanzania, for example, a PCG that began in 2005 was disbanded in 2008 because of excessive bureaucracy. Financial institutions felt that the PCG duplicated other loan assessment processes and was slow to pay out.

One country that appears to have increased lending to small- and medium-size enterprises via PCGs is Rwanda (Berg and Fuchs 2013), where take-up by banks to lend was positive. One of the key reasons for this success was the fact the scheme was developed in close cooperation with the private sector, which suggests that other nations in the region would do well to adopt a similar approach when developing their schemes. 
In addition to providing financial capital to parallel entrepreneurs, government policy should also focus on addressing the lack of quality management expertise through the development of context-specific training. Currently, the small number of organizations focusing on developing management capacity — such as the African Management Initiative (a joint venture of the Association of African Business Schools, the Global Business School Network, Canada's Lundin Foundation, and the Lagosbased Tony Elumelu Foundation) (Furlonger 2012) are non-profits. Another problem is that management training in Africa continues to be Western-oriented, with students encouraged to develop business plans for single businesses in a way that reflects teaching styles of US and European business schools and the profiles of most US and European entrepreneurs. However, as this chapter has tried to make clear, the profile of an African entrepreneur is often very different. African entrepreneurs would therefore benefit immensely from being exposed to culturally relevant and customized training programs that advise them on how to manage multiple businesses, often at the level of micro- and small-size operations, and how to function in the unique and often unpredictable African business environment. Developing these kinds of courses is a complex and location-specific task, and as a result, governments should strongly consider partnering with consulting firms, academia, and relevant firms in the private sector.

\section{Research}

The quality of management training in Africa would benefit from targeted research. In recent years, there has been a gradual increase in academic interest in parallel entrepreneurship (Sieger et al. 2011). Research has concentrated on highlighting the reasons entrepreneurs have adopted a portfolio approach to capitalize on business opportunities. At this stage, the general consensus from the likes of Alsos and Ljunggren (2006), for example, is that there are three types of parallel entrepreneurs-opportunity-motivated, income-motivated, and employmentmotivated. The next step, driven by the likes of Antonio Fierro, has been to explore the field of parallel entrepreneurship outside of the 
Western context (Fierro and Cornelius 2013) and in the context of the developing world. Fierro, in particular, discovered through research that selecting a parallel entrepreneurship approach can result in the ability to take advantage of opportunities that otherwise have limited potential in terms of scale and scope.

However, despite these efforts, there is still much more work to be done. To begin with, the research done in the field (e.g., exploring the motivations behind choosing the path of simultaneous ownership) needs to collect more data from Africa, beginning perhaps in countries that have a strong entrepreneurship culture, such as Nigeria and Kenya. This step will allow key stakeholders to gain a customized understanding of what drives African entrepreneurs to stretch themselves to their limits while providing greater insights for governments and education institutions keen to support parallel entrepreneurship. This research should be directed toward answering the question "Who are the leading parallel entrepreneurs in Africa, and what policies can support them in ways that further their growth and lead to the elevation of smaller firms along the supply chain?"

Research also needs to be conducted on the prevalence of parallel entrepreneurship in other regions of the world. Surely the conditions that exist in Africa that promote a culture of owning numerous businesses simultaneously must exist in other parts of the world. Parallel entrepreneurship is widespread in India, for example, and as in Africa, many entrepreneurs in India are trying to capitalize on the multiple moneymaking opportunities in their country. Researchers and practitioners need to better understand the reasons parallel entrepreneurship is so common. How do these entrepreneurs perform compared with their more focused peers? And what are the ways that knowledge transfer could be initiated among like-minded entrepreneurs in the region and perhaps farther afield?

Finally, further research needs to be conducted on the interconnectivity between parallel entrepreneurship and the continent's informal sector. Extensive research on Africa's informal sector has yet to be done. However, the African Development Bank recently released a report saying that $55 \%$ of Sub-Saharan Africa's gross domestic product (GDP) and $80 \%$ of its labor force can be attributed to the informal sector (African Development Bank Group AFDB 2013). These numbers cannot be 
ignored. The suggestion that individuals operating numerous businesses are unregistered has wide-ranging implications across the economy, from lost tax revenue to the promotion of corruption. The report also cites three core issues as the underlying causes for the proliferation of the informal sector-inflated taxation, a sub-optimal regulatory environment, and a lack of property rights. Interestingly, these same conditions also contribute to entrepreneurs taking the parallel entrepreneurship route. It seems apparent, therefore, that before one can look to optimize the performance of the continent's parallel entrepreneurs, more needs to be done to ensure that they feel comfortable enough to step out, moving from the shadow economy into the formal economy.

\section{Conclusion}

Parallel entrepreneurship is one of the most defining aspects of Africa's entrepreneurship landscape. In today's world, where entrepreneurship is the "in thing" and entrepreneurs are seen as quasi-revolutionaries, parallel entrepreneurship acts as a striking differentiator between Africa and much of the rest of the world.

A combination of push (unpredictable business environment, unemployment, and lack of quality middle managers) and pull (positive societal attitudes and increased economic opportunities) factors have contributed to the prevalence of parallel entrepreneurship on the continent. However, after spending time on the ground in Africa, whether it be in Nigeria, South Africa, or Kenya, for example, one cannot help but feel that even in the absence of these push and pull factors, parallel entrepreneurship would still thrive-because it is highly apparent that parallel entrepreneurship is embedded in the minds of Africans. Improve management standards and curb corruption, and parallel entrepreneurship would still thrive. It is simply the way business is done, and this fact needs to be appreciated by all observers.

This chapter has explored the key implications of parallel entrepreneurship for how business is conducted in the region. From identifying unique challenges, such as moral hazard, that arise when looking to share resources across business holdings in a portfolio to selecting an 
optimal legal structure that will be tax and investment efficient, the parallel entrepreneur has quite a lot of unique challenges to think about. And this entrepreneur would be in a stronger position to circumvent these challenges if he or she were better supported by two key stakeholdersgovernment and researchers. Government support is needed to help alleviate financial and managerial constraints (through grants and sponsored management training programs), and research is needed to help deepen our understanding of parallel entrepreneurship in Africa. The topic matters-yet little is presently known about this social and business phenomenon that characterizes virtually the entire continent of Africa. When one considers the fact that this innovative approach to entrepreneurship has, if properly managed, the potential to materially advance the living standards of millions of the continent's citizens, then it becomes even more apparent that much more needs to be done to realize its potential.

In summary, parallel entrepreneurs are an undeniable force in Africa's entrepreneurial landscape. These multitasking workhorses are driving economic activity across the continent and are one of the most distinctive indicators of Africa's increasing prosperity. However, for these individuals to elevate their performance and take the continent even further, much more needs to be done to increase all stakeholders' understanding of this exciting phenomenon. It is through collective understanding and action that positive steps can be transformed into giant steps toward economic prosperity.

\section{References}

Adcorp. (2014). Adcorp employment index. Adcorp. http://www.adcorp.co.za/ Industry/Pages/Adcorp’sEmploymentIndex.aspx. Accessed 23 Feb 2016. African Development Bank Group (AFDB). (2013). Recognising Africa’s informal sector. AFDB Blog. http://www.afdb.org/en/blogs/afdb-championinginclusive-growth-across-africa/post/recognizing-africas-informal-sector11645/. Accessed 23 Feb 2016.

African Economic Outlook (AEO). (2008). Youth unemployment. AEO. http:// www.africaneconomicoutlook.org/en/theme/developing-technicalvocational-skills-in-africa/tvsd-in-specific-contexts/youth-unemployment/. Accessed 23 Feb 2016. 
Almeida, H., \& Wolfenzon, D. (2006). A theory of pyramidal ownership and family business groups. Journal of Finance, 61(6), 2637-2680.

Alsos, G., \& Ljunggren, E. (2006). Types of portfolio entrepreneurs: Motivations, characteristics and performance. Frontiers of Entrepreneurship Research, 26(6), 10.

Balunywa, J. W. (2009). Portfolio entrepreneurs and economic growth: The case of Uganda: PhD dissertation. Stirling: University of Stirling.

Berg, G., \& Fuchs, M. (2013). Bank financing of SMEs in five Sub-Saharan African countries: The role of competition, innovation, and the government (Policy Research working paper no. WPS 6563). Washington, DC: World Bank.

Bindra, S. (2012). In Africa, it's not enough to run one business, ask 'parallel' entrepreneurs. Business Daily Africa. http:/www.businessdailyafrica.com/ In-Africa-its-not-enough-to-run-one-business/-/539444/1441270//6pnshb/-/index.html. Accessed 23 Feb 2016.

Bugnacki, J. (2015). Critical issues facing Africa: Terrorism, war and political violence. American Security Project. http://www.americansecurityproject.org/critical-issues-facing-africa-terrorism-war-and-political-violence/. Accessed 23 Feb 2016.

Fierro, A., \& Noble, N. (2013). Directions for a new African entrepreneurship research agenda: Parallel entrepreneurship as a solution to Africa's impending employment dilemma. Frontiers of Entrepreneurship Research, 33(17), 233-234.

Fierro, M., \& Cornelius, A. (2013). Portfolio entrepreneurs in Malawi: The role of risk and the environment in the process of portfolio creation and growth. Edinburgh: University of Edinburgh Press.

Filmer, D., \& Fox, L. (2014). Youth employment in Sub-Saharan Africa, Africa development series. Washington, DC: World Bank.

Friedman, M. and Kuznets, S. (1945). Income from independent professional practice. National Bureau of Economic Research. http://www.nber.org/chapters/c2325.pdf. Accessed 23 Feb 2016.

Furlonger, D. (2012). Africa needs more managers. Financial Mail. http://www. financialmail.co.za/business/2012/09/28/africa-needs-more-managers. Accessed 23 Feb 2016.

GEM (2015). Global Entrepreneurship Monitor 2014. http://www.gemconsortium.org/report. Accessed 23 Feb 2016.

Hauge, J. (2014). Africa's economic 'rise' does not reflect reality. The Guardian. http://www.theguardian.com/global-development/poverty-matters/2014/ sep/03/africa-economic-rise-does-not-reflect-reality. Accessed 23 Feb 2016. 
Mead, N. (2012). Youth unemployment takes shine off Africa's economic growth. The Guardian. http://www.theguardian.com/global-development/2012/ may/28/african-economic-outlook-2012-youth-unemployment. Accessed 22 Feb 2016.

Nesta (2014). Startup studios - A better model to build startups? Nesta. http:// www.nesta.org.uk/blog/startup-studios-better-model-build-startups-1. Accessed 23 Feb 2016.

New York Times (NYT). (1999). Yale to erase alumni debts in 2 loan plans. New York Times. http:/www.nytimes.com/1999/04/13/nyregion/yale-to-erasealumni-debts-in-2-loan-plans.html. Accessed 23 Feb 2016.

Nkem-Eneanya, J. (2015). How a poor orphan boy from Kenya became a mega tycoon, meet Chris Kirubi. Rising Africa. http://www.risingafrica.org/successstories/business/meet-the-man-who-relaxes-by-working-even-harder-chriskirubi/. Accessed 23 Feb 2016.

Omidyar Network and Monitor Group. (2013). Accelerating entrepreneurship in Africa. Omidyar Network. https://www.omidyar.com/insights/acceleratingentrepreneurship-africa-report. Accessed 23 Feb 2016.

Rigoglioso, M. (2011). Despite shortage of management talent, Africa a good investment. Insights by Stanford Business. https:/www.gsb.stanford.edu/ insights/despite-shortage-management-talent-africa-good-investment. Accessed 23 Feb 2016.

Rosa, P. (1998). Entrepreneurial process of business clusters and growth by habitual entrepreneurs. Entrepreneurship Theory and Practice, 22(4), 43-44.

Sieger, P., Zellweger, T., Nason, R. S., \& Clinton, E. (2011). Portfolio entrepreneurship in family firms: A resource-based perspective. Strategic Entrepreneurship Journal, 5(4), 327-351.

Short, J. L. (2008). From command-and-control to corporate self-regulation: How legal discourse and practice shape regulatory reform. Ann Arbor: ProQuest.

Simkovic, M. (2011). Risk-based student loans. Washington and Lee Law Review, $70(1), 527$.

Taylor, I. (2015). Dependency redux: Why Africa is not rising. Review of African Political Economy, 43, 1-18.

The Economist. (2012). African entrepreneurs - Parallel players. The Economist. http://www.economist.com/node/21557373. Accessed 22 Feb 2016.

The Economist. (2013). Africa rising - A hopeful continent. The Economist. http://www.economist.com/news/special-report/21572377-african-liveshave-already-greatly-improved-over-past-decade-says-oliver-august. Accessed 22 Feb 2016. 
Transparency International. (2014). Corruption perceptions index 2014: Results. Transparency International. https://www.transparency.org/cpi2014/ results. Accessed 22 Feb 2016.

United Nations Conference on Trade and Development (UNCTAD) (2014). Catalysing investment for transformative growth in Africa. Geneva: UNCTAD. Westhead, P., \& Wright, M. (1998). Novice, serial and portfolio founders: Are they different? Journal of Business Venturing, 13(3), 173-204. 


\title{
Conversation \#13
}

\section{The Hustling Entrepreneur on Trial}

\author{
Mikul Shah of EatOut and \\ Ritesh Doshi of Naked Pizza
}

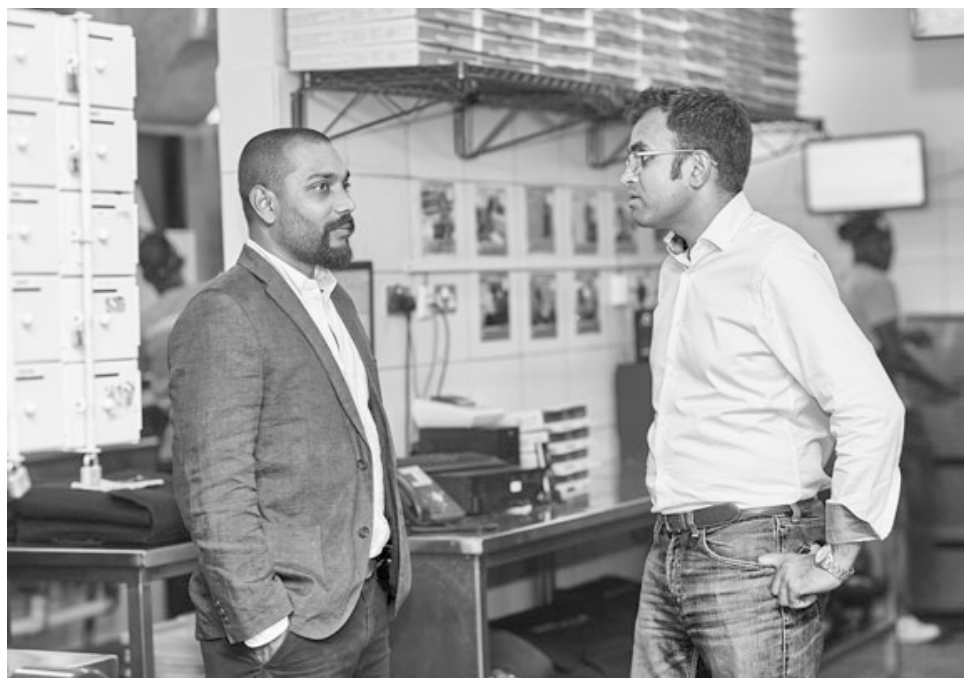

Mikul Shah is the founder of Africa's online restaurant guide EatOut and a selfproclaimed foodie and travel buff. Born and raised in Mombasa, he spent over a decade in the UK before returning to Nairobi to join his family business. In 2010, over a dinner conversation with friends, he realized there was a gap in the market for a comprehensive online restaurant guide for the city. What started out as a hobby financed by a US\$1000 investment is now an award-winning portal, seating thousands of diners at hundreds of restaurants a month. Over the years, EatOut has added several innovative brands to its portfolio, including a monthly 
free-distribution print publication called Yummy Magazine, the annual Nairobi Restaurant Week event, and the Taste Bar \& Restaurant Awards. In 2013, EatOut raised capital from the Netherlands' Africa Media Venture Fund to expand into the East African region. Beyond EatOut, Mikul plays an active role as a mentor, advisor, and investor for several businesses. He co-founded SleepOut. com, which was named as one of CNN's top African start-ups in 2014, and has invested in brands such as Ghafla, Nairobi Garage, OkHi, and Naked Pizza. He also serves as an advisor to Safaricom's Spark innovation fund.

On a visit home to Nairobi in 2011, Ritesh Doshi, a Kenyan financier living in Jordan, was frustrated that he could not get a pizza delivered in under an hour. So unlike most financiers, he quit his day job and decided to do something about it. Ritesh, a self-proclaimed "serial entrepreneur stuck in a financier's body," studied at the London School of Economics and launched his career working for financial institutions such as Credit Suisse, HSBC, and Probitas Partners, a private equity firm. In 2012, Ritesh founded Naked Pizza, Nairobi's premier fast-delivery all-natural pizza restaurant. He is also an active angel investor in the Kenyan start-up scene, having made investments in $\mathrm{OkHi}$, BookNow, and EcoPallets. In addition, he is an independent director of Tropical Heat, a popular brand of snacks and spices, and is the President of the Kenya chapter of the Entrepreneurs' Organization. In May 2016, Ritesh successfully sold Naked Pizza to Pizza Hut.

\section{How would you describe the Kenyan "hustling" culture and its link to entrepreneurship?}

Ritesh: The Kenyan culture of hustling is rooted in doing anything and everything to make the extra buck or, in extreme cases, to make ends meet. Many professionals, from bankers and lawyers to entrepreneurs and doctors, have a side hustle, with the aim of generating additional income, ideally passively. Sometimes, these hustles turn out to be much larger opportunities than an individual's main business or career and become his or her primary business.

Mikul: Biashara, as it is termed in Kiswahili, has a deep root in our culture, and many Kenyans have an almost built-in spirit of entrepreneurship. Most Kenyans have a side hustle mainly to help them afford an aspirational lifestyle, whether it is to purchase a car or a mobile phone or to provide access to better education and health care for their families. 


\section{What is your opinion of hustling? Is it a useful strategy for doing business in Kenya? What are the pros and cons from the entrepre- neurial, employee, and investor perspectives?}

Mikul: Having a side hustle is great in some aspects because it allows you to generate a substantial additional income. However, building a significant brand presence and a scalable business models takes dedication and tenacity. As an investor, I would not be willing to finance an entrepreneur who is not willing to dedicate all of his or her time and efforts to their main business. From an employer's point of view, this entrepreneurial spirit can be very detrimental to the success of a business. No employer would be willing to waste company resources and paid time on an employee's hustle unless they had something to gain, too. Yummy has several team members who earn extra income through their own food blogs — and we have managed to set out a symbiotic relationship that benefits both parties. Yummy gains additional traffic through back links, and the bloggers build their knowledge and experience in the hospitality industry. But it is important to be candid and lay the ground rules from the outset.

Ritesh: I actually think hustling is a distraction. It usually ends up meaning that you try a whole bunch of things until something worksoften without focus on anything except the short-term income generated. By nature, entrepreneurs have a lot going on in their heads with all they are doing. A side hustle, or business, if it can even be called that, is a distraction. For an employee, I think there are actual ethical issues with it, unless you are doing it $100 \%$ in your free time-but in reality, we all know that never happens. If I am paying someone to be at work, I want their mind, body, and heart $100 \%$ committed when they are at work. From an investor's perspective, I would actually not invest with someone who had a side hustle, because to me, it means they are only thinking short-term.

\section{Would you also describe yourself as a hustling entrepreneur?}

Ritesh: If it is the Kenyan definition, then no. But if by hustling you mean doing whatever it takes to get something done-which is what is required of an entrepreneur focused on his or her business - then yes. Start-ups require focus and $150 \%$ of an entrepreneur's time. Trying to 
do a few things half-heartedly would mean that I would not be able to get anything done well. Having said that, I have been involved in a number of start-ups but have limited my involvement to the initial idea and ongoing advice, and have let the other co-founders run with it.

MikuL: I would say yes. But it has always been important to me to ensure that a competent team and strategy are in place before moving on to a new opportunity. Fairly early on, we realized that EatOut needed to achieve two main goals. The first was to ensure that we were seen as the market leaders and were able to sustain our position. This meant diversifying our product portfolio to include offline activities such as Nairobi Restaurant Week, the Taste Awards, and Yummy. All these activities helped cement our position as an authority within the industry while increasing our revenues and profits. The company's general manager oversees these projects, with little or no input from me-which has allowed me to concentrate on our second goal, introducing a more scalable transactional revenue model and expanding to new countries, starting with Rwanda and Uganda. We have recently launched a gift-voucher solution in Kenya and are actively working on pilots with several banks for mobile payments at restaurants.

\section{How did you get into starting and investing in new (side) businesses? Would you consider those side hustles?}

MikuL: One of the key challenges that many start-ups face in Kenya is developing trust. EatOut's early success and its reputation as a market leader and innovator allowed me to build a considerable network in the hospitality and technology sectors over the years. I therefore saw an opportunity to be able to "open doors" for other start-ups, giving them access to investors, partners, and collaborators. However, I am not actively involved in these businesses on a day-to-day level, so I do not consider them to be side hustles.

Ritesh: Once an entrepreneur develops credibility, opportunities flow toward you - though this can also be the beginning of the end if your focus is diverted too much. In my case, building a successful business in a short timeframe meant lots of opportunities coming my way. But I have been judicious and have only ever invested in businesses to which there was some connection to my core business and where I could really add 
value with my knowledge and network. I will never take an operating role, and I always wear the hat of the shareholder — so they are definitely not side hustles.

\section{What is your main recommendation for the hustling entrepreneurs out there?}

Ritesh: Stop being involved in too many things. Seriously. Pick a business you are passionate about, can and want to do all day long, every day, and focus on it. Lack of focus limits your ability to develop knowledge, deep relationships, and experience to ultimately become successful in your chosen area-and potentially limits your growth, success, and ability to achieve your full potential in life.

MikuL: I think the advice remains the same for all businesses. First, there should be a strong and diverse team who are all vested in the business. In terms of skill sets, it is an advantage to have people who have good experience with legal, marketing, sales, and technology. In most cases, spending time in the corporate world helps to build experience and networks that can in turn help you determine whether an idea is worth pursuing. Second, start-ups should focus on execution. Our brainstorming whiteboard sessions at EatOut are arguably the most fun part of what we do, and we come up with hundreds of new ideas every day. But the truth is that we have very limited time and resources, which is why it is important to focus and prioritize. Settling on a clear focus-your product, your audience, your strategy — is critical from day one. Finally, there is no substitute for hard work. We try to have a lot of fun at the same time. Work hard and play hard, and the rewards will come. But it is also always important to remember that there is nothing wrong with trying and failing. If you are going to fail, make sure it happens quickly, pick yourselves up, and start again.

\section{What was your biggest "Aha!" moment when it comes to doing business in Africa?}

MikuL: The biggest difference from developed markets (e.g., Silicon Valley) is that start-ups in our region have to focus on revenues at a fairly early stage. Kenyan investors look at profitability above almost everything else. In other markets, growth potential based on users and traffic is much 
more important, and it is common to see large investments in start-ups that have no revenue model in place. Second, the Kenyan market is relatively small, and technology businesses that can expand regionally are more attractive for investors.

Ritesh: Business is hard everywhere; it is even harder in Africa. Everything takes longer, costs more, and there is more bureaucracy than you can imagine. My "aha" is having enough cash to see through the increased costs and time taken, and developing a lot of patience when things happen pole, pole ["slowly, slowly"].

\section{You have tested quite a few different market opportunities. Can you give some examples? Why did some work out? And why did you decide not to pursue others?}

Mikul: Our main goal with EatOut at the moment is to ensure that we have Number-One market share within the industry, and we have therefore explored many different opportunities. Our magazine Yummy and activities such as Nairobi Restaurant Week have done well to generate revenue and increase our presence as an industry authority. We recently decided to explore the e-gift voucher market, allowing consumers to purchase and redeem digital gift vouchers securely online, tapping into a multi-billion-shilling industry (the shilling is the Kenyan currency) and providing easy gift solutions for the diaspora. In 2016, our aim is to have pop-up stores in high-traffic locations such as supermarkets and malls. On the other hand, we decided not to continue with an online restaurant delivery pilot due to the fact that there were already a number of start-ups concentrating on the same thing. We also felt that the market was simply not large enough to justify a heavy investment in building the logistics infrastructure and customer service team required to service it.

Ritesh: We have tested a number of opportunities, from alcohol delivery and a mobile juice bar concept to providing third-party logistics to other consumer brands. The reasons why most of those concepts were not feasible as standalone businesses were mainly centered around two themes.

Number one was the size of market. As interesting as some of these businesses may have seemed on the surface, some of them just did not have a large enough customer base for the business to be sustainable. Let me 
give you an example: We tried alcohol delivery to customers at home. It was a logical extension from the delivery of beer and wine at Naked Pizza that customers usually purchase alongside their food order. We saw a natural path to move into home delivery of alcohol, given that the customers trusted us, we had the infrastructure with bikes and storage facilities in place, and we had sufficient supplier relationships. In reality, we found that most middle-class consumers would prefer to "be seen" drinking their premium alcohol of choice in a public venue rather than enjoying it at home. The more affluent customers who were willing to consume premium alcohol in the comfort of their own homes either had the means to make own arrangements by sending their driver or simply had it in stock. The space that was left for us with customers who wanted premium alcohol delivery on demand was not large enough to justify a stand-alone business.

Number two was the willingness to pay. We piloted third-party lastmile logistics for a number of B2B players. They all expected a premium service, which meant a rider who was well spoken, well versed in terms of maps, driving a reliable bike with a clean uniform and possessed a box that safeguarded the items from rain. That is all good. However, sadly they were not willing to pay the costs associate with that kind of quality service. We usually heard things like "But my boda boda [motorcycle taxi] guy only charges me half the amount." After five months, with that mindset in place, we just had to pull the pilot.

\section{Thank you, Mikul and Ritesh!}

\footnotetext{
(c) (1) This chapter is distributed under the terms of the Creative Commons Attribution 4.0 International License (http://creativecommons.org/licenses/by/4.0/), which permits use, duplication, adaptation, distribution and reproduction in any medium or format, as long as you give appropriate credit to the original author(s) and the source, provide a link to the Creative Commons license and indicate if changes were made.

The images or other third party material in this chapter are included in the work's Creative Commons license, unless indicated otherwise in the credit line; if such material is not included in the work's Creative Commons license and the respective action is not permitted by statutory regulation, users will need to obtain permission from the license holder to duplicate, adapt or reproduce the material.
} 